\title{
The Inspiration from the Manjusri Wisdom below the Vision of Education: the Significance of "the only proper course to take" and the Wisdom of the Middle Way
}

\author{
Liu Shulin \\ China Jiliang University \\ Hangzhou, Zhejiang, China
}

\begin{abstract}
In traditional Chinese culture, Buddhism culture is an important and wonderful part, especially the wisdom of Manjushri is respected and worshipped by the general public. In the new era, what is the development trend of Manjusri Wisdom. This paper is to study the wisdom of Manjusri against the background of the new era. Manjusri wisdom is not only a valuable asset of Chinese traditional culture, but also of great significance for cultivating socialist builders and successors in the new era.
\end{abstract}

Keywords-Education; Manjusri wisdom; The only proper course to take; Middle wisdom

\section{INTRODUCTION}

We live in the material world, the material desires are always in the shadows, tempting our hearts all the time, the hearts are fascinated, the heart turns with the environment, and finally we are bound by material desires to sink. Especially in the new era, the development of science and technology is becoming more and more rapid, and our vision has also expanded rapidly. At the same time, our material desires have become more and more inflated. The temptation is constant, the sorrow is constant, and the self is lost. Manjusri wisdom can strengthen our will, so that when we face the infinitely expanding material desire, we will not change our original intention for the temptation of the moment, and will not prevent us from losing ourselves in the material world. At the moment, Manjusri wisdom gives us a lot of reference.

Under the wisdom of Mahayana Buddhism, it is widely praised that Manjusri wisdom, also known as "Great Wisdom Manjusri", is the representative and symbol of Buddhist wisdom. Only by the re-understanding and reinterpretation of the present, can the wisdom of ancient times regain its radiance in the new era, and it will continue to ignite a new vitality in the contemporary era. Manjusri wisdom is like the wisdom of the "love broke out in love" described by Lausanne Tudan Joan, [1], the wisdom infiltrated is not only the precious wealth of Chinese traditional culture, but also the cultivation of socialist builders in the new era. And successors are also important.

Buddhism, as many scholars believe, is a kind of philosophical wisdom with its own unique wisdom. As the wisdom and traditional culture of the East leave us a precious spiritual legacy, we are still far from studying it. The value and meaning contained in it are not adapted to the current environment, so we need the spiritual meaning of the wisdom of Manjusri. It is only in this way that we can re-interpret, rationally abandon and innovate and reconstruct in the new era and new environment. Only in this way can we find unique modern values and modern meanings from Manjusri wisdom.

\section{PREDICAMENT OF EDUCATION IN THE NEW ERA}

Since the modern times, especially since the reform and opening up, China's science and technology and productivity have been unprecedentedly developed, creating enormous material wealth, spiritual wealth and cultural wealth for the people, thus satisfying people's survival needs and development needs to a large extent. At the same time, it has also encountered an unprecedented crisis of modernity. "After God's death, people seem to be dead too." The infinite expansion of material desires and the dissatisfaction of the spirit lead people to accidentally fall into the trap of social alienation, enslaved by their own things, and eventually become slaves of material desires and become wanderers who are spiritually homeless.

Ecological crises, mentality crises, value crises and moral crises have emerged one after another. Humans think they have found the light, but they don't know that they have been swallowed up by the so-called light. "Human evolution of IQ, degraded wisdom; developed technology, played down the humanities; chased the fashion, but forgot the original words that the ancient wise men have already reminded." I have to admit that the most savage and primitive forces are lurking in the most civilized and most developed places. It is not the mountains and the bottomless abyss that often make us rush. Many scholars believe that the philosophical root cause of the crisis of modernity is the dominance of rationalism and the infinite expansion of material desire, but it has not realized that the essence of the problem is the lack of human care and the absurdity of love.

From the spiritual world of contemporary Chinese, the mental crisis of Chinese personality identification may be more prominent than that of Westerners, because we must not only face the invasion of Western globalization, but also face the collapse of our traditional value system, traditional culture. 
Lost and other issues. China is a tradition, especially the Chinese tradition.

\section{THE ONLY PROPER COURSE TO TAKE AND THE WISDOM OF THE MIDDLE ROAD}

The Manjusri method of the Mahayana Sutra is like the treasure of the Buddha, and it is the first righteousness, the difference is no difference, and the method is not retreating. "The gamma room" said: "The Sayādaw said, all rely on the righteousness." "The Dagger Bodhisattva has no clear and clear divisions" said: "The decapitation of the various places can be said, he wants to speak, but the bounds." "Determining the Vini Sutra" said: "The method of Manjusri's teachings is based on liberation." According to the rules of the law, according to the law, the liberation of the law, and the characteristics of the Manjusri method, fully in line with the "clean and pure Nikon" . "Manjusri's Li Famen" is not like the disrespect. It depends on the physical and mental activities of the people before the present - the implication, the position, the boundary, the origin, the second guide, and the self-realization of the victory, the legal world, the liberation, the direct The opening of the show allows people to get into the moment. This can be said to be different from the Mahayana.

In the early Mahayana Sutra, the "Manjusri Method" was the same as the "Pan Ruo Fa Men" (in "Original Prajna"), and it had a unique development. In terms of sentences, "all are based on victory", "but the boundaries of the saying" (near the Zen's special mention). Focusing on troubles is Bodhi, lust is Bodhi, and sin is Bodhi, but neglecting kindness - faith, blasphemy, blasphemy, etc. are Bodhi, good work, good news is Bodhi, six degrees, four unlimited, four photos, etc. is Bodhi . In terms of action, it is a foreign language to go outside, to go to the palace, the lascivious woman to live in peace, to defend the Buddha, and to pay attention to the inherent teaching methods of Buddhism. This can be said to be the "bias" in all equality! This kind of "biased" spirit is manifested in many aspects in the "Manjusri Method".

The method of Manjushri Bodhisattva has always been thought to be "empty"; as the inheritance of the ancient three sects, it is to push the Manjusri as a distant ancestor. However, in the "empty" "prajna" (the first five sessions), Manjushri did not participate in the question and answer, which is worth noting! "Chinese version of the prajna", and "the original translation of the "Chinese translation", "Wu translation", although there are Manjushri at the meeting, but "the next prajna" of the "Gold translation", "Qin translation", "Song translation", Did not mention Manjusri Shili. Therefore, the method of Manjushri's teachings, even if it is said to be "empty", may be indirectly related to the "prajna method" rather than the same system.

"Buddhism" refers to the world view and methodology of knowing and treating things in Buddhism. "No. 2" is also called "no two", that is, from the air, there are two sides. The so-called "two" means "differentiation" and "distinction". Secondly, it can mean both presence and absence, and can also refer to life and death. It can also refer to color and space. The so-called "not only" refers to the realization of various distinguishing realms that transcend the right and wrong between everything and phenomena through practice.

The wisdom of Manjushri's "two ways" and the wisdom of the middle can be said to be the fruit of transcendence and sublimation. Manjusri wisdom can provide a different value reference for the reconstruction of modern civilization. Among them, the spirit of humanistic care and transcendence embodied in "disengagement-freedom", the spirit of compassion and the feelings of salvation are reflected in "not dying of life, not ignoring nirvana" and deconstructing with "first" The wisdom and spirituality embodied in the "two-dimensional" harmony, the "reverse-pull" transformation, the "hidden interpretation", and the "three-dimensional" enlightenment can give us profound inspiration.

\section{The ENLIGHTENMENT FROM THE PERSPECTIVE OF EDUCATION}

The unique wisdom of Manjusri can reawaken to some extent the often neglected consciousness lurking in our hearts, reawaken the lost self, remember the lost memories, and reactivate our humanistic care and love. heart of. Although Manjusri wisdom contains many idealistic ideas that need to be abandoned, its own transcendence, the only way to deal with contradictions, and the wisdom of the middle of the road, still in the perspective of contemporary education. It has important reference value and is a valuable asset in our spiritual world. If we can extract beneficial nutrition from the wisdom of Manjusri and derive and transform it into the ecological wisdom, moral wisdom, peace wisdom, harmonious wisdom and psychological wisdom that modern people need, then the oldest oriental wisdom will be renewed. Renewing vitality and becoming an inexhaustible source of value for building an advanced culture.

First of all, we should have a transcendental dimension beyond birth. In the current education, the excessive materialization pursuit and neglecting the moral humanistic care will make people indulge in the sensory enjoyment and give up the spiritual pursuit. It is easy to be materialized and animalized, resulting in the loss of the noble and dignity that human beings should eventually end up.

"Our education should be less arranged, more self-reliant; less restrictions, thank you for guidance; less understanding, more fun. In a word, we must respect people, understand people, care for people, and train students into 'people'. "We must be aware of the power of the spirit and the value of the emotions, be aware of what is really needed in the depths of our hearts, and realize the true meaning of human happiness, so that we can be enslaved rather than enslaved by things, living in the world and detached. In the secular world, complete the spiritual transcendence in the return. In fact, when we humans have been obsessed with the infinite plundering of nature, it is easy to lead to the expansion of desire and bring endless greed and desire to mankind. When I look back and ask myself, I discover the source of happiness that has been deeply hidden in my heart, thus discovering and developing our own resources to prevent our own loss. Perhaps this will construct the simplest, most harmonious and most The civilized model of sustainable development. This transcendental spirit of transcendence is the 
promotion and vigilance of human beings and a valuable asset in the process of human civilization.

In addition, we also need a kind of wisdom that is harmonious and multi-dimensional. Manjusri wisdom helps to open up various oppositions, barriers and contradictions in social life, and achieve new integration of all things in the world, both in terms of identity and harmony; in the process of world integration, Manjusri wisdom will become a The driving force of the process, and will accelerate the process of integration, help people and society, people and people, people and their own harmonious coexistence, is conducive to shaping a harmonious education and teaching environment.

This kind of wisdom is spread all over the wisdom of many sages and modern philosophers both at home and abroad, and needs to be sorted out and communicated at a new level. For example, Fang Dongmei, one of the "modern neo-Confucians", believes that the "main theoretical system of Huayanxue can greatly demonstrate the vast harmony of Chinese people in philosophical intelligence" and guides the basic principles of "general harmony" in Chinese culture. Next, "When creativity transcends destructiveness, harmony also overshadows disputes. What existed at that time is the spiritual triumph of fulfilling the ideal of life according to human nature." This is inspiring for us to build a "harmonious society" today.

Finally we need love and spirituality. In a world that is not caring for each other, not harmonious, and indifferent between people, there is no difference between a man and a hard labor in a world full of walking dead. There are too many inconveniences, sufferings and pains in human life. We need to comfort with love. We need emotions to influence, and we need the touch of the soul to wake up the deepest embarrassment. "As long as they give each other, they can get each other. Many people have evolved from 'preservers' to 'wise people'. It is not only valuable, but it is far from enough. It should be further promoted by wisdom. For a 'lover': love the truth, love nature, love others, this is also the best love for yourself." In addition, facing the infinite material world, the dialectical unity rationality and logical thinking based on contradictions and opposites sometimes Struggling, we still need to use lively spirituality to grasp. A spiritual world is a world full of vitality and innovation.

Everything in the world is complemented by the ontology. This is the fundamental connotation of Manjusri's prajna wisdom and the only proper course to take. Prajna wisdom and the law are intrinsically linked, and equal relationships exist between them. The so-called phenomenon is only different. One manifests itself in the illusion of outside. We must not only see the illusion to see the essence, but also understand the identity of the illusion, so that we can get liberation and transcendence; when the prajna blooms, the opposites and differences will become mutually integrated, such as the shore and the other shore. The whole and the part, the phenomenon and the ontology have one more and more, big and small, long and short, hidden and obvious, good and bad, etc. The dialectical wisdom and the contradictions reflected in it are large and tolerant. The spirit of the present, under the new era of the new era, still has important value and significance in the contradictory international society.

\section{CONCLUSION}

In the new era, only a better moral construction can better support socialist construction. This requires each citizen to consider the relationship between the individual and the society, dialectically treat the contradiction between the individual and the society, and need to get rid of the short-term private interests. Going out of the narrow personal limitations, fully demonstrating the spirit of human beings surpassing themselves.

The alienation and tension of various relationships in campus life, such as people, people and things, things and things, have led to a series of practical problems such as teaching imbalance and private desire expansion, in the final analysis, or because we lack A "two-way method" and the wisdom of the middle road. In the campus life, we regularly carry out moral education publicity activities, educate our students to be a moral person and a person with transcendence, start from small things, start from scratch, and establish a harmonious and stable campus life.

If we can learn from the wisdom of Manjusri and learn the "two ways" and the wisdom of the middle, and can derive and transform from the new ideas into the vision of the new era, then the oldest oriental wisdom will be re-emerged. New vitality will become a valuable asset for building socialism with Chinese characteristics and help us cultivate socialist builders and successors.

\section{REFERENCES}

[1] Multi-intelligence - Lausanne Tudan Qiong Pai. The wisdom that broke out in love [M]. Gansu: Gan Su Nationality Publishing House.

[2] Seng Zhao "Notes on the Vikings" [M] Shanghai: Shanghai Ancient Books Publishing House. (In Chinese)

[3] Zhao Puchu "Buddhist knowledge answer" [M] Beijing: Religious Culture Press. (In Chinese)

[4] David Griffin. Postmodern Science [M]. Beijing: Central Compilation and Publication Society. (In Chinese)

[5] Longshu "Great wisdom" [M] Shanghai: Shanghai Ancient Books Publishing House. (In Chinese)

[6] Xiao Limin Miao Qi, the middle of the road: the humanistic spirit in Manjusri's Wisdom, Journal of Zhangzhou Teachers College - 2004-0229. (In Chinese)

[7] Peng Tu Manjusri wisdom "Wutai Mountain" - 2015-03-18(In Chinese)

[8] Xiao Limin The modern value and eternal revelation of Manjusri wisdom; - Wutaishan. (In Chinese)

[9] Wan Nianyi The Modern Value and Eternal Enlightenment of Manjusri Wisdom - 2013. (In Chinese) 